\title{
Postmortem computed tomography is an informative approach for prevention of sudden unexpected natural death in the elderly
}

This article was published in the following Dove Press journal:

Risk Management and Healthcare Policy

3 May 2010

Number of times this article has been viewed

\author{
Toshihiro Kaneko ${ }^{1,2}$ \\ Miyuki Hibi' \\ Miki Ishibashi' \\ Atsuhiro Nakatsuka ${ }^{2,3}$ \\ Yukinari Omori ${ }^{4}$ \\ Ken Ishikura ${ }^{4}$ \\ Tsuyoshi Hatada ${ }^{4}$ \\ Taichi Takeda ${ }^{4}$ \\ Yoshiyuki Takei ${ }^{1,2}$ \\ Kan Takeda ${ }^{3}$ \\ 'Department of Patient Safety, \\ ${ }^{2}$ Autopsy Imaging Center, ${ }^{3}$ Department \\ of Radiology, ${ }^{4}$ Emergency Department, \\ Mie University Hospital, Japan
}

Introduction: Less than $10 \%$ of unnatural death cases have been examined by autopsy in Japan. In particular, the causes of death in the elderly have not yet been actively investigated. Here, we evaluated the possible use of postmortem computed tomography (PMCT) to investigate the causes of sudden unexpected natural death (SUND) in the elderly.

Methods and subjects: Death cases confirmed within 24 hours since the onset of symptoms at the Emergency Department of Mie University Hospital were defined as sudden death cases. A total of 212 sudden death cases, including 175 SUND cases, that occurred in a 3 -year period from September 2006 to August 2009 were investigated.

Results and discussion: The number of sudden death cases was highest in patients in their seventies (56 cases, 26\%), followed by patients in their eighties and sixties. Sudden death occurred more in men than in women in their fifties to seventies, while it occurred more in women than in men over the age of 90 . PMCT was performed in more than $80 \%$ of SUND cases regardless of age of the deceased. The causes in 26 cases $(27.1 \%)$ were established by PMCT, many of which were hemorrhagic diseases. Signs of aortic aneurysm rupture were detected by PMCT in the thoracic and abdominal areas of 8 patients in their seventies and over, whereas signs were absent in the younger group. Also, more than $18 \%$ of sudden death cases in patients in their seventies and over were bathing-related sudden death (BRSD). BRSD was rarely caused by hemorrhagic diseases, suggesting that a drop in blood pressure caused by bathing is an important factor in BRSD.

Conclusion: PMCT is a method that is relatively acceptable by bereaved families. It is useful for establishing the causes of approximately $30 \%$ of the SUND cases examined. The PMCT findings suggested that early detection and treatment of thoracic and abdominal aortic aneurysms and preventive measurements of bathing-related drop in blood pressure are important for the prevention of SUND in the elderly.

Keywords: sudden unexpected natural death (SUND), postmortem computed tomography (PMCT), bathing-related sudden death (BRSD)

\section{Introduction}

Reporting unnatural death (death without obvious causes) to the police is obligatory, and autopsy is necessary to investigate the precise cause of death. However, in Japan, the number of cases examined by autopsy is less than $10 \%$ of all unnatural death cases, ${ }^{1}$ which is significantly lower than the rates in Europe and North America. ${ }^{2-6}$ One of the reasons is that there are only about 150 forensic scientists in Japan. In addition, cutting remains using a scalpel is traditionally not acceptable among Japanese. Under the current situation, the precise causes of death are investigated in a small number of cases, and the exact causes of death resulting from crimes and accidents
Correspondence:Toshihiro Kaneko Department of Patient Safety, Mie University Hospital, 2-174 Edobash, Tsu Mie, Japan

$\mathrm{Tel}+8 \mathrm{I} 5923 \mathrm{I}, 5307$

$\mathrm{Fax}+81592315308$

Email kaneko-t@clin.medic.mie-u.ac.jp 
are unconfirmed. Furthermore, the credibility of statistics on the causes of death, which is the base of medical and welfare policies, may come into question.

Sudden unexpected natural death (SUND) is defined as sudden unnatural death excluding the possibility of exogenous death. In Japan, wherein the medical examiner system is not well established, SUND cases are not considered as police matters based on the lack of external injury signs, and therefore SUND is the least investigated area. It is also speculated that some SUND cases were considered as natural death instead of unnatural death at the doctor's discretion. In particular, many bereaved families are against autopsy for investigating the precise causes of SUND in the elderly, and thus cases were often treated as cardiopathy-related cases from the doctor's speculation. ${ }^{7}$

On the other hand, postmortem computed tomography (PMCT), a computed tomographic approach for examining the deceased, is a powerful tool for investigating the causes of death. ${ }^{8-10}$ PMCT has been used mainly in the emergency department. It has neither been included in the medical fee point system nor has been well recognized. Comprehensive reports on PMCT are currently limited.

Here, we report useful insights gained from investigation of the causes of SUND in the elderly using PMCT.

\section{Methods and subjects}

Death cases that were confirmed within 24 hours of the onset of disorders at the emergency department of Mie University Hospital were defined as sudden death cases. A total of 212 sudden death cases that occurred in a 3-year period from September 2006 to August 2009 were investigated. Mie University hospital is a teaching hospital with a capacity of 707 beds, and is the core medical facility in the region with a population of 300,000-400,000. The emergency department does not have an emergency medical center, but receives 600-700 patients transferred by emergency service.

PMCT was performed within one hour after confirming death in the emergency department, and the scanning range is assumed to be from the head to the thighs using a 64-channel multidetector row CT scanner (Aquilion 64: TOSHIBA Medical System, Tokyo, Japan). The scan parameters were as follows. For the head: conventional scan mode, $120 \mathrm{kV}$, $250 \mathrm{~mA}, 1 \mathrm{sec} /$ rotation, and $8 \mathrm{~mm}$ collimation; for the neck: helical scan mode, $120 \mathrm{kV}, 200-450 \mathrm{~mA}, 0.75 \mathrm{sec} /$ rotation, and $5 \mathrm{~mm}$ collimation; for the thorax, abdomen, pelvis, and thighs: helical scan mode, $120 \mathrm{kV}, 200-400 \mathrm{~mA}$, $0.5 \mathrm{sec} /$ rotation, and $5 \mathrm{~mm}$ collimation (lung field: $2 \mathrm{~mm}$ collimation). Diagnostic imaging is first performed by an emergency doctor and the subsequent cross-check is carried out by a radiologist.

The mortality and morbidity committee (MMC) of the hospital evaluates all cases of confirmed death monthly for signs of crimes and accidents, and for the appropriateness of medicine. All subjects in this study were evaluated by the MMC. We used PMCT to compare SUND in the elderly with SUND in the younger group, and discussed the causes and prevention of SUND in the elderly. Although cases of death at the time of bathing are often treated as exogenous deaths, such as unforeseen drowning, we defined them here as bathing-related sudden death (BRSD).

\section{Ethical considerations}

Written informed consent to perform PMCT and use obtained data for medical research purposes was obtained from all families of the deceased. Notably, the Ethics Committee of the University Hospital recommends the use of PMCT for the investigation sudden death.

\section{Results}

There were 212 cases of sudden death at the emergency department of Mie University Hospital in the 3-year period from September 2006 to August 2009. Of these 212 cases, PMCT was performed in 170 cases and autopsy was carried out in only one case, which is a case of exogenous death and not of SUND. The total number of sudden death cases that occurred each month in the 3-year period was highest in February, which was 7-fold higher than the total number of sudden death cases that occurred in the lowest month, that is, June (Figure 1). The number of sudden death cases was highest among those in their seventies (56 cases, 26\%), followed by those in their eighties and sixties. There were no significant differences in the usage rates of PMCT by age (Figure 2). Table 1 shows the usage rates of PMCT by causes of death. Among sudden death cases, more than $80 \%$ of SUND cases were examined by PMCT; however, a lower percentage of exogenous death cases appeared to be evaluated by PMCT.

The number of SUND cases in men in their fifties to seventies were more than that in women in the same age range, whereas differences in the number of SUND cases became smaller between men and women in their eighties and the trend was reversed in their nineties (Figure 3 ).

As shown in Table 2, reliability of the causes of death was classified into 4 levels based on the combination of PMCT findings and available information (eg, witness statement and past history of health problems). A total of 144 SUND cases 


\section{Persons}

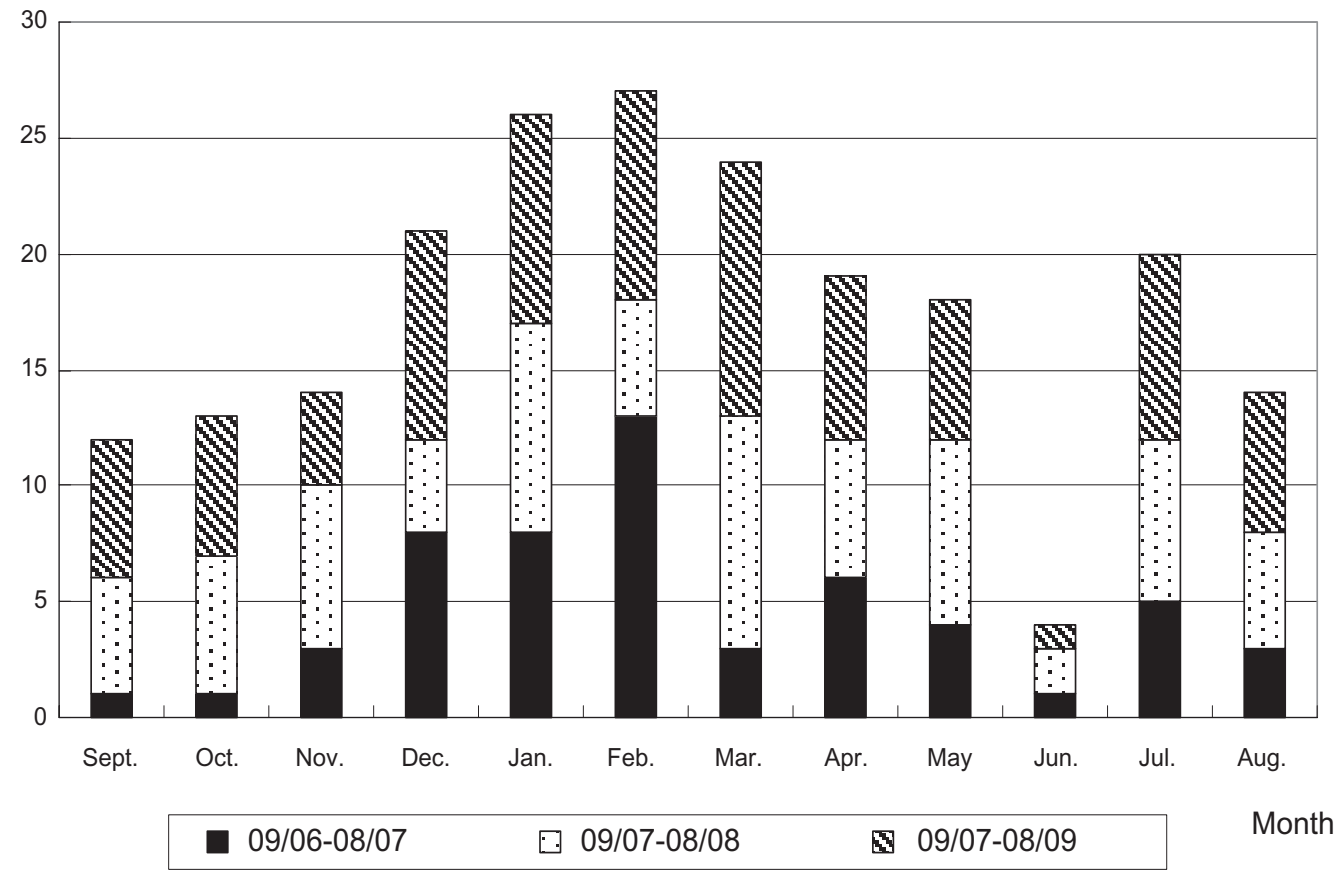

Figure I Number of sudden death cases at the emergency department of Mie University Hospital in a 3-year period. There were 212 sudden death cases in a 3-year period from September 2006 to August 2009. The total number of monthly cases in 3 years was highest in February (27 cases), which was about 7-fold the number of cases of the lowest month (June, 4 cases).

were examined by PMCT and were classified into 4 groups according to reliability level. Figure 4 shows the distribution of the 4 groups. The level A group, where the causes of death are established, represented $27.1 \%$ of the total cases. The level B and C groups accounted for $4.9 \%$ and $11.1 \%$ of the total cases, respectively, whereas the level D group, which showed no significant positive findings by PMCT, comprised $56.9 \%$ of the total cases.

Detailed causes of death in the level A group as established by PMCT are presented in Table 3. Many of these

\section{Persons}

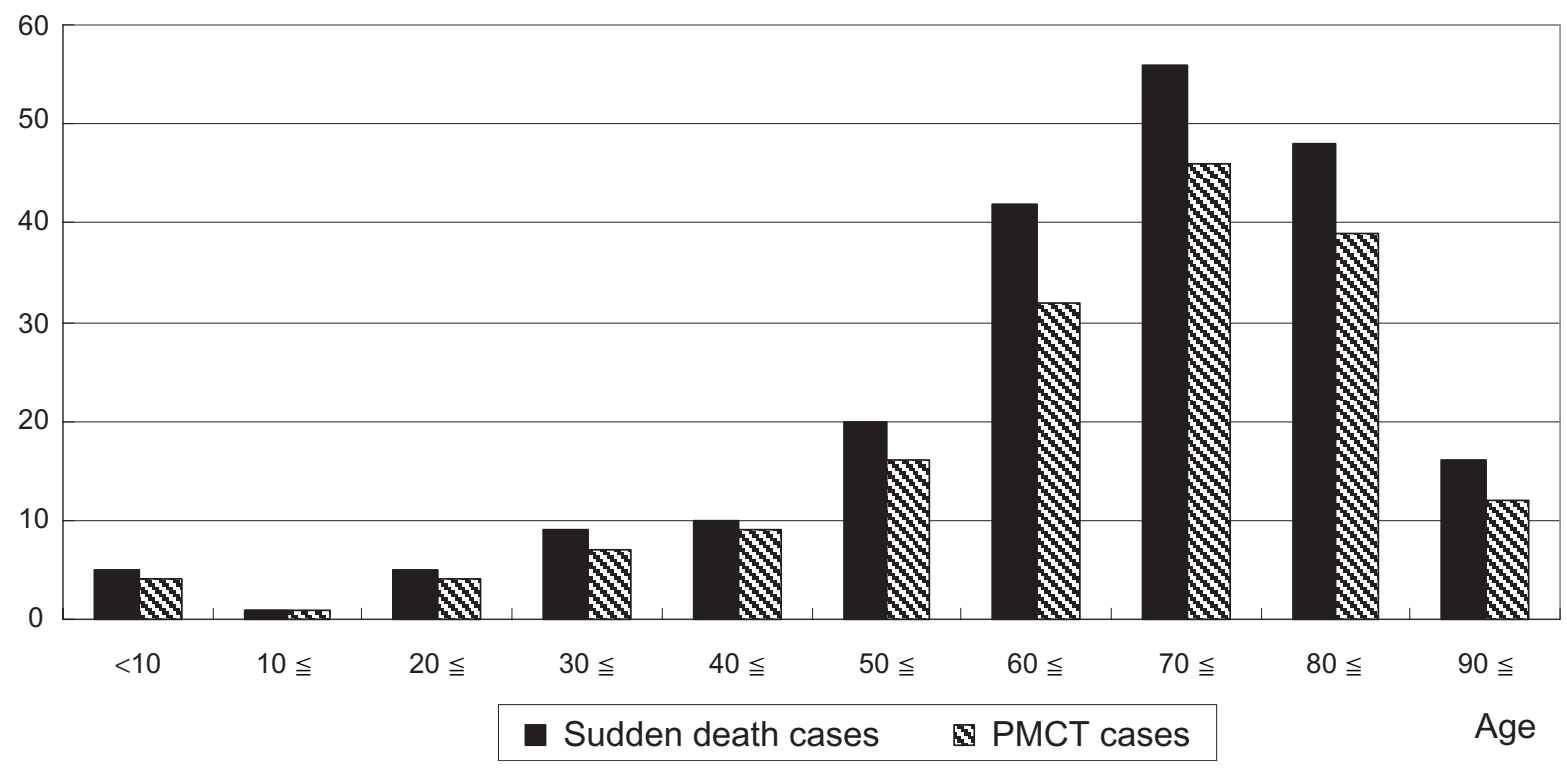

Figure 2 Number of sudden death cases by age and number of cases examined by postmortem computed tomography (PMCT).The number of sudden death cases was highest in the elderly in their seventies ( 56 cases, $26 \%$ ), followed by the elderly in their eighties and sixties. PMCT was performed widely regardless of patient age. 
Table I Rates of sudden death cases examined by PMCT

\begin{tabular}{llll}
\hline Cause of death & $\begin{array}{l}\text { Sudden death } \\
\text { cases }\end{array}$ & PMCT cases & $\begin{array}{l}\text { Execution rate } \\
\text { of PMCT }\end{array}$ \\
\hline SUND & 175 & 144 & 823 \\
Exogenous death & 37 & 26 & 72 \\
Total & 212 & 170 & 802 \\
\hline
\end{tabular}

Abbreviation: PMCT, postmortem computed tomography.

cases were caused by hemorrhagic diseases, and bleeding associated with lung cancer and marked pneumonia were also found. Other causes included strangulated ileus and suffocation due to pharyngeal cancer. Among 26 patients over the age of 70 in the level A group, signs of thoracic and abdominal aortic aneurysm rupture were found in 8 cases. On the other hand, signs were absent in the younger generations in the level A group.

BRSD is a common form of sudden death among the Japanese elderly. We found that BRSD was common in winter and rare in summer (Figure 5). As shown in Table 4, $18 \%$ of sudden deaths in the elderly over the age of 70 were BRSD. The causes of 2 cases of BRSD were established as subarachnoid hemorrhage and brain hemorrhage from PMCT findings.

\section{Discussion}

PMCT has been performed mainly in the emergency department, and since the PMCT system is not yet officially approved as being covered by health insurance system in Japan, few comprehensive statistical data are presently available. In our hospital, death is regarded as the most important outcome in medicine. In this regard, the hospital initiated a systematic investigation of the causes of all death cases from September 2006. It has also continuously encouraged the use of PMCT for this purpose.

PMCT was used for the evaluation of SUND cases in all age groups (Figure 2), indicating that rejection of PMCT due to old age was rare. PMCT is a noninvasive, rapid and simple approach, and is considered more easily accepted by confused bereaved families of the deceased who died by sudden death than other methods. The present findings indeed highlighted the versatility of PMCT. Among the cases not examined by PMCT, only one was due to rejection by a bereaved family and the others were attributable to the unavailability of CT facilities being used in normal medical exercise. This suggests that PMCT is useful for investigating the causes of SUND in the elderly, which is often not supported by bereaved families. As shown in Table 1, the usage rate of PMCT tended to be lower in exogenous death cases than in SUND cases. This is due to the fact that some exogenous death cases, such as suicide by hanging and road accidents, clearly show evidence of the causes of death on the body. The number of sudden death cases in men, which peaked in their seventies, was generally more than that in

\section{Persons}

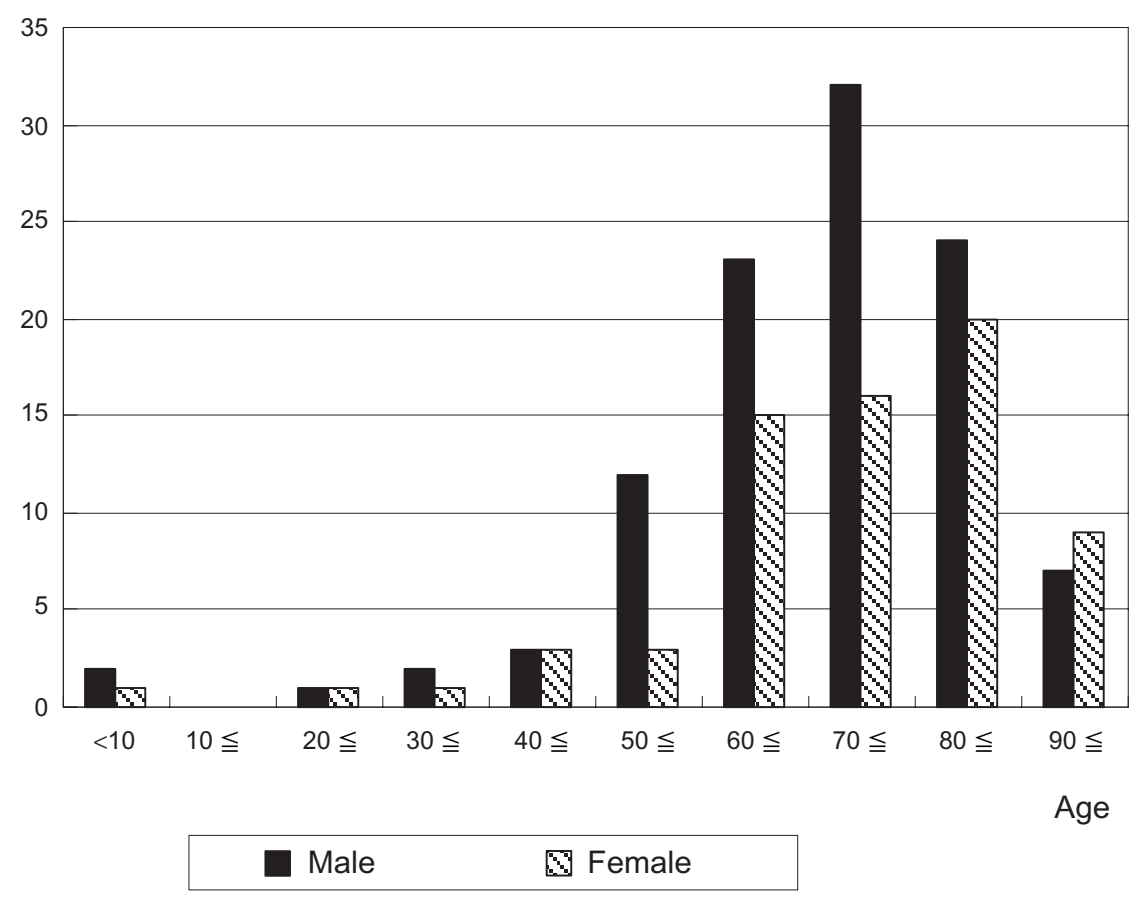

Figure 3 Number of sudden unexpected natural death (SUND) cases by age and sex.The number of SUND cases was higher in men than in women in their fifties to seventies. The differences became smaller in their eighties, and the trend was reversed in their nineties. 
Table 2 Reliability levels of the causes of sudden death cases predicted from PMCT findings and supporting information

\begin{tabular}{|c|c|c|c|}
\hline Level & Reliability level of inferred cause of death & PMCT findings & Supporting information \\
\hline A & Possible to establish & Direct indication of endogenous sudden death & Not required \\
\hline B & Inferable with considerable reliability & $\begin{array}{l}\text { Possible association with endogenous sudden } \\
\text { death }\end{array}$ & Presence of supporting information \\
\hline C & Inferable with low reliability & $\begin{array}{l}\text { Possible association with endogenous sudden } \\
\text { death }\end{array}$ & Unknown \\
\hline $\mathrm{D}$ & Negative for hemorrhagic diseases & None & Not required \\
\hline
\end{tabular}

Abbreviation: PMCT, postmortem computed tomography.

women, which peaked in their eighties. These results are in good agreement with the trends shown by Tokyo Medical Examiner's Office, which performs the largest number of autopsies in Japan. ${ }^{11}$

When inferring the causes of death from PMCT findings, cases with PMCT findings that directly indicate the causes of death, such as subarachnoid hemorrhage and ruptured great vessels, were classified as the level A group. Cases with PMCT findings that are possibly associated with the causes of SUND and with accompanying supporting information were classified as the level B group (causes of death are inferable with considerable reliability). A case with PMCT findings of coronary artery calcification supported by a witness statement describing chest pain when collapsing was classified as the level B group. Furthermore, cases with PMCT findings that are possibly associated with the causes of SUND with no supporting information were classified as the level $\mathrm{C}$ group (causes of death are inferable with low reliability). Cases with no significant PMCT findings were classified as the level D

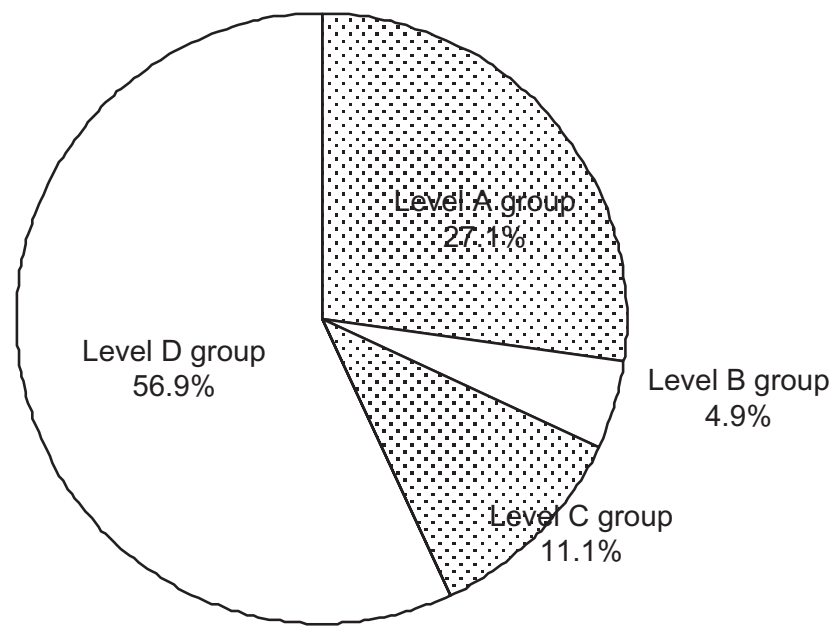

Figure 4 Reliability levels of causes of sudden death inferred from PMCT findings and supporting information. The level A group, wherein the causes of sudden death can be established from PMCT findings, comprised $27.1 \%$ of all cases examined by PMCT, whereas the level B group, wherein the causes of sudden death are inferable with considerable reliability, accounted for $4.9 \%$ of the total cases. The level $C$ group, wherein the causes of sudden death are inferable with low reliability, and the level $D$ group with no significant PMCT findings represented $\mathrm{II} .1 \%$ and $56.9 \%$ of the total cases, respectively Abbreviation: PMCT, postmortem computed tomography. group (Table 2). Even in the level D group, ruptured great vessels and lethal intracranial hemorrhage can be ruled out from the possible causes of death; furthermore, accidents and crimes, of which the signs of the cause of death are not detectable by external examination, can be ruled out. Therefore, a lack of significant PMCT findings is also informative for the elimination of the possible causes of death. It is believed that PMCT can establish the causes of slightly less than $30 \%$ of sudden death cases. In this study, the causes of $27.1 \%$ (level A group) and $4.9 \%$ (level B group) of SUND cases, that is, a total of $32 \%$ of SUND cases, were established.

It is desired that the final confirmation of the causes of death be carried out by autopsy. Also, it is necessary to evaluate the usefulness of the recently introduced postmortem MRI. ${ }^{12}$ In our hospital, there is an established postmortem procedure for inpatient cases wherein autopsy follows PMCT. However, cases in this study involved deaths of outpatients, and this postmortem procedure was not applied to any SUND cases. Therefore, there was no corresponding autopsy result to compare with PMCT findings. In addition, MRI is not included in the postmortem procedure in our hospital. PMCT is believed to be highly useful when used for cases of death due to external injuries. In fact, even in these preferred cases, the concordance rates between PMCT and autopsy results ranged between $46 \%$ and $100 \% .^{13}$ Therefore, careful consideration is required in inferring the causes of SUND cases based on PMCT findings. Also, changes following death and those resulting from an attempt of resuscitation should be taken into consideration. As for the case of severe pneumonia in the level A group in the present study, cardiopulmonary resuscitation was not undertaken and the case was examined by PMCT within $30 \mathrm{~min}$ after respiratory arrest. Taken together, this case was categorized as level A on the basis of lung field findings showing severe pneumonia and the trachea being filled with mucus. However, it remains inconclusive whether PMCT is useful for establishing the causes of certain SUND cases that are not due to hemorrhagic diseases such as aortic rupture and subarachnoid hemorrhage. To address this problem, further studies performing PMCT 
Table 3 Causes of SUND cases established based on PMCT findings by age

\begin{tabular}{llll}
\hline Cause of death & $<\mathbf{7 0}$ years (male/female) & $>\mathbf{7 0}$ years (male/female) & Total (male/female) \\
\hline Rupture and acute dissociation of aorta & $4(2 / 2)$ & $6(3 / 3)$ & $10(5 / 5)$ \\
Rupture of thoracic aortic aneurysm & 0 & $6(3 / 3)$ & $6(3 / 3)$ \\
Subarachnoid hemorrhage & $4(0 / 4)$ & $1(0 / 1)$ & $5(0 / 5)$ \\
Brain hemorrhage & $1(1 / 0)$ & $3(1 / 2)$ & $4(2 / 2)$ \\
Pneumonia & $2(1 / 1)$ & $2(0 / 2)$ & $4(1 / 3)$ \\
Lung cancer & $2(2 / 0)$ & $1(1 / 0)$ & $3(3 / 0)$ \\
Rupture of abdominal aneurysm & 0 & $2(2 / 0)$ & $2(0 / 2)$ \\
Others & 0 & $5(3 / 2)$ & $5(3 / 2)$ \\
Total (male/female) & $13(6 / 7)$ & $26(13 / 13)$ & $39(17 / 22)$ \\
\hline
\end{tabular}

Abbreviations: PMCT, postmortem computed tomography; SUND, sudden unexpected natural death.

in combination with autopsy and/or postmortem MRI are necessary.

Among the causes of 39 sudden death cases established by PMCT, rupture of aortic dissection as well as thoracic and abdominal aortic aneurysm was found in 18 cases, which represented $12.5 \%$ of 144 SUND cases examined by PMCT. In this study, BRSD cases were included in SUND cases, but when 22 BRSD cases were excluded, $14.8 \%$ of SUND cases were associated with aortic problems. Among the disease-induced death cases that received postmortem examination (considered to reflect SUND cases) performed by the Tokyo Medical Examiner's Office, cases related to aortic and capillary disorders were found in $3.2 \%$ and $3.9 \%$ of the total cases in 2007 and 2008, respectively. ${ }^{11}$ Approximately 20\% (20.1\% in 2007 and 20.5\% in 2008) of cases of postmortem examination were performed by autopsy in the Tokyo Medical Examiner's Office; thus, aortic disorders may be missed or misdiagnosed as other types of diseases for cases that had not been examined by autopsy. This may be the reason for the lower rates of aortic disorders obtained than our present results. On the other hand, our hospital widely accepts emergency patients in the region, and PMCT is performed on $82.3 \%$ of outpatient SUND cases. Based on the fact that PMCT can identify almost all cases of sudden death caused by aortic rupture, our data more likely reflect the actual percentage of aortic rupture in sudden death cases than other data. Therefore, the number of SUND cases caused by aortic rupture may be considerably higher than what is generally expected in Japan. Furthermore, all 6 cases of SUND caused by rupture of thoracic and abdominal aortic aneurysms were elderly over 70 years of age, and among them, only 1 case was previously diagnosed with a thoracic aortic aneurysm. Thoracic aortic aneurysms at high risk of rupture are considered

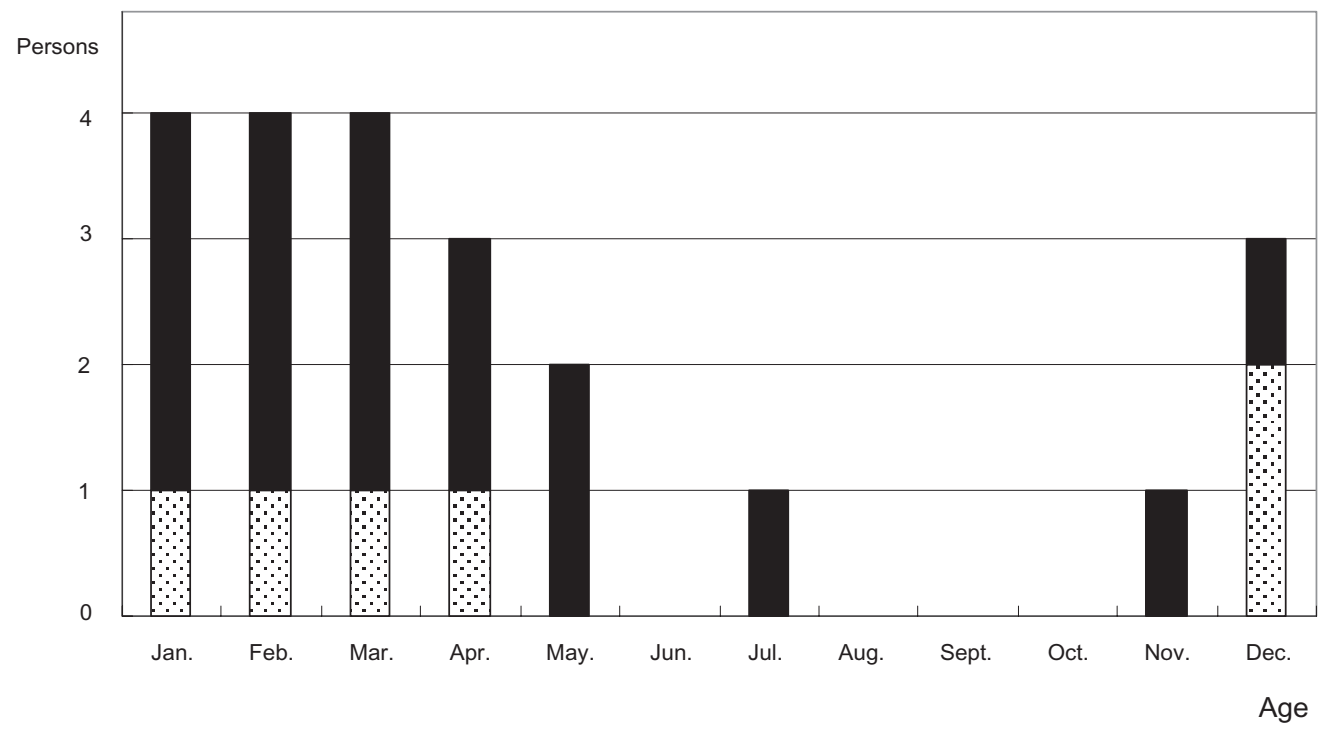

Figure 5 Numbers of bathing-related sudden death (BRSD) cases by month. BRSD was common in winter, and 70\% of BRSD cases occurred in the elderly over the age of 70 years. 
Table 4 Number of BRSD cases by age and reliability of causes of BRSD inferred by PMCT

\begin{tabular}{|c|c|c|c|c|c|c|c|}
\hline \multirow[t]{2}{*}{ Age } & \multirow[t]{2}{*}{ SUND } & \multirow[t]{2}{*}{ BRSD } & \multirow[t]{2}{*}{$\begin{array}{l}\text { BRSD/ } \\
\text { SUND }\end{array}$} & \multicolumn{4}{|c|}{$\begin{array}{l}\text { Precision of presumed cause } \\
\text { of BRSD by PMCT findings }\end{array}$} \\
\hline & & & & $\begin{array}{l}\text { Level } \\
\text { A }\end{array}$ & $\begin{array}{l}\text { Level } \\
\text { B }\end{array}$ & $\begin{array}{l}\text { Level } \\
\text { C }\end{array}$ & $\begin{array}{l}\text { Level } \\
\text { D }\end{array}$ \\
\hline \multirow[t]{2}{*}{70} & 55 & 6 & $10.9 \%$ & I & 0 & 0 & 5 \\
\hline & 89 & 16 & $18.0 \%$ & 1 & 0 & 5 & 10 \\
\hline Total & 144 & 22 & $15.3 \%$ & 2 & 0 & 5 & 15 \\
\hline
\end{tabular}

Abbreviations: BRSD, bathing-related sudden death; PMCT, postmortem computed tomography; SUND, sudden unexpected natural death.

to be detectable by chest X-ray, thus rupture could have been prevented or delayed by conventional routine health check-ups. More precise statistics of aortic rupture may become available with the wider use of PMCT in the future, and this will enable the application of more commonly used procedures (eg, chest X-ray and strict control of blood pressure) in preventing sudden death caused by aortic rupture in the elderly.

Cases of death during bathing are normally considered as unforeseen deaths by drowning and are therefore categorized into exogenous deaths. However, it is unlikely that a person who is able to take a bath by himself (or herself) suddenly encounters problems during bathing without inducement; therefore, we classified such cases as BRSD or SUND. According to the conventional categorization, if 'sudden death in a bathtub' is written in death certificates (postmortem examination certificates), this type of death is considered exogenous death and is considered as BRSD. On the other hand, if 'lethal arrhythmia' was written, deaths during bathing are not considered as BRSD. To include these cases and obtain the actual numbers of BRSD, we examined all sudden death cases during bathing and confirmed from the medical records that these cases were BRSD regardless of the contents of the certificates. The estimated annual number of BRSD cases in Japan is approximately $14,000,{ }^{14}$ which is thought to be slightly less than $10 \%$ of the total sudden death cases in Japan. Moreover, $80 \%$ of BRSD cases occurred in the elderly over 65 years of age, ${ }^{15}$ Here, we found that BRSD accounted for $18 \%$ of SUND cases in the elderly over 70 years of age. BRSD was also reported in the US, suggesting the potential danger of bathing; however, the incidence rate of BRSD in the US appeared to be $1 \%-10 \%$ of that in Japan. ${ }^{16-18}$ This may be due to the Japanese custom wherein people prefer to have a deep (up to the neck line) and hot bath. In particular, a drop in blood pressure due to vasodilation was suggested to cause various adverse effects. ${ }^{19}$ In this study, intracranial hemorrhage was established by
PMCT as the cause of death in two BRSD cases (level A group). The lower rate of hemorrhagic diseases in BRSD cases than in total sudden death cases indicated the possibility that a drop in blood pressure and dehydration during bathing, rather than a rise in blood pressure at the start of bathing, are strongly involved in BRSD. The incidence of BRSD is as high as that of road accident-caused death, and we believe that PMCT is useful for elucidating the actual conditions of BRSD, a very important cause of sudden death in the elderly. The elucidation of BRSD concepts, as well as the promotion of the use of PMCT, is necessary to utilize PMCT-employed investigation for the prevention of BRSD.

\section{Conclusion}

PMCT is a postmortem examination approach for determining the cause of sudden death, and this procedure is relatively acceptable among bereaved families. This approach enabled the identification of the causes of approximately $30 \%$ of the SUND cases examined. The PMCT findings indicate that the incidence of aortic rupture causing sudden death is possibly higher than the expected incidence. In particular, the necessity of taking precautions against rupture of a thoracic aortic aneurysm in the elderly was suggested. BRSD is a crucial cause of sudden death in the elderly, and $18 \%$ of SUND cases in the elderly over the age of 70 were identified as BRSD in this study. It was suggested that PMCT is useful for elucidating the actual conditions of BRSD, and that the conditions caused by a rise in blood pressure at the start of bathing are not as important as those caused by the following drop in blood pressure. Elucidation of BRSD concepts, together with promotion of the use of PMCT, is necessary for BRSD prevention.

\section{Acknowledgments}

Part of this research was conducted through financial support from the Center for Health Promotion in Community and Workplace of Mie University and Diwa Health Foundation.

\section{Disclosures}

No conflicts of interest were declared in relation to this paper.

\section{References}

1. Data from The Sankei Shimbun and Sankei Digital [online]. Accessed 2010 Mar 31. Available from: http://sankei.jp.msn.com/affairs/ trial/080123/tr10801231049000-n1.htm

2. Data from The National Academies Press [online]. Accessed 2010 Mar 31. Available from: http://books.nap.edu/openbook.php?record_ $\mathrm{id}=10792$ \& page $=12$. 
3. Rutty GN, Duerden RM, Carter N, Clark JC. Are coroners' necropsies necessary? A prospective study examining whether a "view and grant" system of death certification could be introduced into England and Wales. J Clin Pathol. 2001;54(4):279-284.

4. Eriksson L, Sundström C. Decreasing autopsy rate in Sweden reflects changing attitudes among clinicians. Qual Assur Health Care. 1993;5(4):319-323.

5. Rainio J, Sajantila A. Fatal gunshot wounds between 1995 and 2001 in a highly populated region in Finland. Am J Forensic Med Pathol. 2005;26(1):70-77.

6. Kalediene R, Starkuviene S, Petrauskiene J. Seasonal patterns of suicides over the period of socio-economic transition in Lithuania. BMC Public Health. 2006;6:40.

7. Ikeda K, Kamimura H. Studies on characteristics of cause of death in Japan. Annual Report of Tokyo Metropolitan Research Laboratory of Public Health. 1998;49:321-327. [in Japanese].

8. Leth PM. Computerized tomography used as a routine procedure at postmortem investigations. Am J Forensic Med Pathol. 2009;30(3): 219-222.

9. Scholing M, Saltzherr TP, Fung Kon Jin PH, et al. The value of postmortem computed tomography as an alternative for autopsy in trauma victims: a systematic review. Eur Radiol. 2009;19(10):2333-2341.

10. O'Donnell C, Woodford N. Post-mortem radiology-a new subspeciality? Clin Radiol. 2008;63(11):1189-1194.

11. Data from Tokyo Medical Examiner's Office Statistics database [online]. Accessed 2010 Mar 31. Available from: http://www.fukushihoken. metro.tokyo.jp/kansatsu/database/index.html
12. Thayyil S, Chandrasekaran M, Chitty LS, et al. Diagnostic accuracy of post-mortem magnetic resonance imaging in fetuses, children and adults: A systematic review. Eur J Radiol. 2009; Nov 10 [Epub ahead of print].

13. Scholing M, Saltzherr TP, Fung Kon Jin PH, et al. The value of postmortem computed tomography as an alternative for autopsy in trauma victims: a systematic review. Eur Radiol. 2009;10:2333-2341. Epub 2009 May 21.

14. Takahashi R. Why do bathing accidents happen for the elderly? Community Health. 2004;35:53-57. [in Japanese].

15. Yasuhara M. Accidents for middle and old aged persons while bathing in the cold season: From the viewpoint of forensic medicine. Nihon Iji Shinpo. 2000;3996:21-25. [in Japanese].

16. Bundnick LD, Ross DA. Bathtub-related drownings in the United States. Am J Public Health. 1985;75:630-633.

17. O'Carroll PW, Alkon E, Weiss B. Drowning mortality in Los Angeles county, 1976 to 1984 . JAMA. 1988;260:380-383.

18. Quan U, Cummings P. Characteristics of drowning by different age groups. Inj Prev. 2005;9:163-168.

19. Nagasawa Y, Komori S, Sato M, et al. Effects of hot bath immersion on autonomic activity and hemodynamics: comparison of the elderly patient and the healthy young. Jpn Circ J. 2001;65(7):587-592.

\section{Publish your work in this journal}

Risk Management and Healthcare Policy is an international, peerreviewed, open access journal focusing on all aspects of public health, policy, and preventative measures to promote good health and improve morbidity and mortality in the population. The journal welcomes submitted papers covering original research, basic science, clinical \& epidemio-

\section{Dovepress}

logical studies, reviews and evaluations, guidelines, expert opinion and commentary, case reports and extended reports. The manuscript management system is completely online and includes a very quick and fair peerreview system, which is all easy to use. Visit http://www.dovepress.com/ testimonials.php to read real quotes from published authors. 